\title{
The MEDD myth: the impact of pseudoscience on pain research and prescribing-guideline development
}

\author{
This article was published in the following Dove Press journal: \\ Journal of Pain Research \\ 23 March 2016 \\ Number of times this article has been viewed
}

With the opioid-misuse and -abuse problem on the rise, pain practitioners and lawmakers are scrambling for strategies to help mitigate opioid risks. Approaches include opioid-treatment agreements, urine drug testing, prescription-monitoring programs, assorted validated risk-assessment tools for abuse/misuse and opioid-induced respiratory depression (OIRD), biopsychosocial support, and other strategies. ${ }^{1-3}$ Nonopioid pain therapies should be considered and maximized prior to initiating opioid treatment; however, in some cases opioids are the optimal choice for both noncancer and cancer-related pain syndromes. ${ }^{4}$

Aside from these strategies to curtail a number of opioid-associated risks, the professional literature ubiquitously employs morphine-equivalent daily dose (MEDD) and other comparable acronyms to attribute escalating risks based on overall daily opioid dose. ${ }^{1,4,5}$ One maneuver that is frequently endorsed to avert OIRD is daily opioid-dose reduction measured by MEDD. ${ }^{6-8}$ Since potency, receptor-binding affinity, physical tolerance, and various pharmacokinetic attributes differ among opioids, the concept of MEDD was employed to justify transitioning from a currently prescribed opioid to one or more opioid "equivalents". ${ }^{9}$ However, the defined daily dosage (DDD) of one opioid does not necessarily exhibit the same effects of the DDD of another opioid. This distinction then creates a problem clinically when opioid consumption is being considered. Svedsen et al, ${ }^{9}$ for example, conducted an analysis comparing DDD and oral morphine equivalent (OMEQ). It should be noted, however, that due to the variations in equivalence calculators and numerous sources having different potencyequivalent estimators, there were several identified limitations to the concept of OMEQ. The authors excluded methadone altogether, due to conversion issues. Nevertheless, methadone is included precipitously throughout the literature as part of MEDD, and has also been attributed to an elevated risk level aside from its calculated MEDD. ${ }^{8}$ Svedsen et al determined that the range of equianalgesic ratios varies dramatically between certain opioids. ${ }^{9}$ For example, when converted to morphine equivalents, fentanyl's conversion ranged from 68 to $150 \mathrm{mg}$, and buprenorphine ranged from 33.3 to $60 \mathrm{mg}$. The authors demonstrated several of the concerns with variations in using OMEQ, and raised the question of why OMEQ is even the standard conversion cited by the medical literature and clinicians.

Considering the plethora of literature that relies on MEDD to assign opioid and public health risks, as well as to study various opioid-prescribing trends, we question
Correspondence: Michael E Schatman CPE I60I, I I4th Avenue SE, Suite I00, Bellevue, Washington, USA 98004 Email headdock@comcast.net (c) (i) (5) 2016 Fudin et al. This work is published and licensed by Dove Medical Press Limited. The full terms of this license are available at https://www.dovepress.com/terms. cc) you hereby accept the Terms. Non-commercial uses of the work are permitted without any further permission from Dove Medical Press Limited, provided the work is properly attributed. For permission for commercial use of this work, please see paragraphs 4.2 and 5 of our Terms (https://www.dovepress.com/terms.php). 
the validity of MEDD as a justifiable parameter on which to rely so heavily. In doing so, we searched the literature for development or validity of daily morphine equivalent using the search terms "morphine equivalent daily dose (MEDD)", "oral morphine equivalent (OMEQ)", "equianalgesic opioid dose", and "morphine equivalents (MEQs)".

Information sources included Medline via PubMed, Access Medicine, CINAHL, Ovid, the National Guideline Clearing House, Google, Google Scholar, Medscape, and eMedicine. Equianalgesic dose was defined as a dose at which two opioids (at a steady state) provided approximately the same pain relief. ${ }^{10}$ Scant data resulted from this search relating to the initial concept of daily morphine equivalence; however, numerous publications and studies revealed flaws in this widely accepted standard of measurement.

Nuckols et al conducted a study in 2014, the purpose of which was to compare and contrast the existing guidelines on the use of opioids for chronic pain. ${ }^{11}$ A total of 13 guidelines were considered eligible for the study. Of the 13 guidelines considered, four determined "high" doses to be greater than $200 \mathrm{mg}$ MEDD. These claims were made on the basis of randomized controlled trials demonstrating pain control achieved at lower doses and observational studies revealing increased adverse events at higher doses. The American Society of Interventional Pain Physicians 2012 guidelines recommend a dosage limit of $90 \mathrm{mg}$ MEDD, based on observational studies detecting an increase in overdoses with greater than $100 \mathrm{mg}$ of morphine equivalent per day used. Eight of the guidelines recommended that higher doses (not specified) should be used with caution. The authors also noted that most guideline recommendations are supported only by observational data or expert recommendations. ${ }^{9,7,12-14}$ Nuckols et al concluded that of the 13 guidelines discussed, there was no consensus as to what actually constitutes a "morphine equivalent". ${ }^{11}$

A significant problem with the concept of MEDD is the lack of a universally accepted opioid-conversion method. ${ }^{15}$ A survey was conducted asking pharmacists, physicians, nurse practitioners, and physicians' assistants to estimate daily morphine equivalents using their reference of choice to convert hydrocodone $80 \mathrm{mg}$, fentanyl transdermal patches $1,800 \mu \mathrm{g} /$ day (equal to $75 \mu \mathrm{g} /$ hour), methadone $40 \mathrm{mg}$, oxycodone $120 \mathrm{mg}$, and hydromorphone $48 \mathrm{mg}$. A total of 319 respondents that were included in the final analysis had a variety of responses, but the most striking were the standard deviations of fentanyl MEDD of $\pm 124 \mathrm{mg}$ MEDD and methadone of $\pm 166 \mathrm{mg}$ MEDD. This study illustrated that utilization of various dosage-conversion tablets and equianalgesic ratios that have been published could lead to dramatic underdosing or fatal overdosing in some cases. In 2014, Shaw and Fudin conducted a survey comparing various online opioid dose-conversion tools and found a $-55 \%$ to $+242 \%$ variation across eight opioid-conversion calculators. ${ }^{16}$ The standard deviations in these two studies alone exceeded many of the MEDD maximums that several states have employed to trigger consultation from a certified pain expert. ${ }^{8,17-19}$ These studies alone unequivocally disqualify the validity of embracing MEDD to assess risk in any meaningful statistical way. Outside of MEDD calculations, there are several factors that also require consideration, but that remain largely ignored. These include patient-specific attributes, such as pharmacogenetics, organ dysfunction, overall pain control, drug tolerance, drug-drug interactions, drug-food interactions, patient age, and body surface area. ${ }^{15}$ The bottom line is that as the scientific concepts upon which prescribing guideline authors depend are flawed and invalid, so are the guidelines themselves. As a result, we posit that these guidelines are disingenuous and highly unethical.

Opiate overdoses unfortunately can occur at any dose, and patients are at risk on even low-dose opioids. Zedler et al developed a risk index for OIRD in the veteran population. This validated risk tool illustrated that in veteran populations, even a daily morphine equivalence of $20 \mathrm{mg}$ /day equates to an increase in OIRD. ${ }^{20}$ Greater risk of OIRD is associated with higher daily morphine equivalence; however, Dasgupta et al concluded that dose-dependent opioid-overdose risk among patients did not have a distinct risk threshold. ${ }^{21}$

While Zedler et al's validated multivariate linear regression model for OIRD clearly established elevated risks for patients with comorbid psychiatric illness, end-organ dysfunction, and more, these items are inherently ignored when establishing state and national guidelines that habitually rely only upon MEDD. These important comorbid liabilities considered in the Risk Index for Serious Prescription OpioidInduced Respiratory Depression or Overdose (RIOSORD) are important parameters that unjustifiably have lacked consideration. ${ }^{20}$ Moreover, if we do rely on drug therapy alone, it is clear that the majority of opioid-related deaths are attributable to a combination of opioids plus sedative hypnotics and/ or alcohol. ${ }^{21}$ If we accept this as fact, assigned risks should be based on an opioid:sedative hypnotic ratio rather than opioids alone. The difficulty here is that elevated risks associated with sedating drugs, such as alcohol, benzodiazepines, imidazopyridines, pyrazolopyrimidines, cyclopyrrolones, various other skeletal muscle relaxants, such as carisoprodol and meprobamate, antidepressants, antipsychotics, anticonvul- 
sants, antihistamines, and many others, have unique inherent risks as single agents. However, while many of these agents are ordinarily prescribed concomitantly, minimal attention has been attributed to their combined risks, most probably because of this unpredictability.

As a final point, we believe that it is important to address the continued utilization of MEDD as a dependent variable in pain research. A PubMed search of recent publications indicates the continued use of this archaic concept in studies of both cancer and noncancer pain. ${ }^{22,23}$ Unlike the zealots who are heavily responsible for recent opioid-prescribing guidelines and trends, we do not necessarily believe that researchers who continue to rely upon the concept of MEDD are being disingenuously agenda-driven in doing so. Rather, researchers' use of MEDD continues to be commonplace, simply because doing so has been conveniently accepted rather than methodically questioned. It is easier to ignore pharmacogenomics and individualized therapy, and "lump" all opioids and patients together based on the denominator of MEDD, as opposed to comparing the impact of an intervention on individual consumption of opioids, such as morphine, fentanyl, and methadone. However, just as prescribing guidelines are based on flawed formulas and evidence, invalid concepts can make research invalid. We are thus compelled to consider whether outcome research that continues to rely upon the concept of MEDD is also invalidated by such. Our hope as researchers is that our colleagues will acknowledge this imbroglio and convert their processes of outcome research in a manner that will produce more valid and meaningful results for individual patients, rather than meaningless cohorts.

Single-dose studies, expert opinion, and observations are largely the source from which equianalgesic tables are derived. ${ }^{10,24}$ With the exception of methadone conversions, published studies have been conducted in noncancer patients and have not accounted for inter- and intrapatient variability. Based on the marked variability of dosing conversions from one opioid to another, the lack of a distinct risk threshold, and various patient variabilities, the concepts of MEDD and daily limits are grossly flawed. How any agency, clinician, or lawmaker can claim a daily limit on total morphine equivalence and/or dispensed dosage units is mind-boggling when there is obviously no accurate, validated, or universally accepted way to calculate total MEDD. Tragically, this is what the United States Centers for Disease Control and Prevention (CDC) Guideline for Prescribing Opioids for Chronic Pain ${ }^{25}$ has done. Simply put, it is scientifically, ethically, and morally inexplicable. Therefore, the flawed concept of MEDD should not necessarily be used to guide clinicians when adjusting opioid doses or rotating from one to another. In our opinion, impressionist lawmakers and antiopioid zealots are basing clinical policy decisions on flawed concepts that ultimately could adversely affect positive outcomes for legitimate pain patients. Let us hope that pain researchers will lead the way in developing a much-needed and ethical paradigmatic revision, as the MEDD myth must be dispelled.

\section{Disclosure}

JF reports the following: Astra Zeneca (speakers bureau, advisory board); DepoMed (advisory board); Endo (consultant); Kaléo (speakers bureau, advisory board); KemPharm (consultant); Millennium Health LLC (speakers bureau, advisory board, expert witness); Practical Pain Management (development of online opioid-conversion calculator); Remitigate LLC (founder, owner); Scilex Pharmaceuticals (consultant); and Zogenix (consultant). The other authors report no conflicts of interest. This editorial represents the opinions of the authors, and has not been reviewed or prepared as part of any government agency or companies listed.

\section{References}

1. Fudin J. Update on Risk Evaluation and Mitigation Strategies (REMS) associated with long-acting opioids. Drug Topics. 2011;155: 45-58.

2. Gourlay DL, Heit HA, Caplan YH. Urine Drug Testing in Clinical Practice. The Art and Science of Patient Care. 6th ed. Bridgewater (NJ): Center for Independent Healthcare Education; 2015.

3. Moeller KE, Lee KC, Kissack JC. Urine drug screening: practical guide for clinicians. Mayo Clin Proc. 2008;83:66-76.

4. Chou R, Fanciullo GJ, Fine PG, et al. Clinical guidelines for the use of chronic opioid therapy in chronic noncancer pain. J Pain. 2009;10:113-130.

5. Federation of State Medical Boards. Model Policy on the Use of Opioid Analgesics in the Treatment of Chronic Pain. Euless (TX): FSMB; 2013. Available from: http://www.fsmb.org/Media/Default/PDF/FSMB/ Advocacy/pain_policy_july2013.pdf. Accessed February 28, 2016.

6. American Society of Interventional Pain Physicians. Guidelines for Responsible Opioid Prescribing in Chronic Non-cancer Pain: Part 2 Guidance. Paducah (KY): ASIPP; 2012.

7. US Department of Veterans Affairs. Clinical Practice Guideline for Management of Opioid Therapy for Chronic Pain. Washington: Department of Defense; 2012.

8. Centers for Disease Control and Prevention. Draft CDC guideline for prescribing opioids for chronic pain. 2016. Available from: http:// www.cdc.gov/drugoverdose/prescribing/guideline.html. Accessed February 24, 2016.

9. Svedsen K, Borchgrevink P, Fredheim O, Hamunen K, Mellbye A, Dale O. Choosing the unit of measurement counts: the use of oral morphine equivalents in studies of opioid consumption is a useful addition to defined daily doses. Palliat Med. 2011;25:725-732.

10. Shaheen P, Walsh D, Lasheen W, Davis MP, Lagman RL. Opioid equianalgesic tablets: are they all equally dangerous? J Pain Symptom Manage. 2009;38:409-417.

11. Nuckols T, Anderson L, Popescu I, et al. Opioid prescribing: a systematic review and critical appraisal of guidelines for chronic pain. Ann Intern Med. 2014;160:38-47. 
12. Institute for Clinical Systems Improvement. Assessment and Management of Chronic Pain. Bloomington (MN): ICSI; 2011. Available from: www.icsi.org/_asset/bw798b/ChronicPain.pdf. Accessed February 21, 2016.

13. American Pain Society. Guideline for the Use of Chronic Opioid Therapy in Chronic Noncancer Pain: Evidence Review. Chicago: APS; 2009. Available from: www.americanpainsociety.org/uploads/pdfs/ Opioid_Final_Evidence_Report.pdf. Accessed March 14, 2016.

14. National Opioid Use Guideline Group. Canadian Guideline for Safe and Effective Use of Opioids for Chronic Non-cancer Pain. Hamilton (ON): National Pain Centre; 2010. Available from: http://nationalpaincentre. mcmaster.ca/opioid. Accessed February 24, 2016.

15. Rennick A, Atkinson TJ, Cimino NM, Strassels SA, McPherson ML, Fudin J. Variability in opioid equivalence calculations. Pain Med. Epub 2015 Sep 9.

16. Shaw K, Fudin J. Evaluation and comparison of online equianalgesic opioid dose conversion calculators. Pract Pain Manag. 2013;13:61-66.

17. Health Care Association of New Jersey. Pain Management Guideline. Hamilton (NJ): HCANJ; 2006.

18. Washington State Department of Labor and Industries. Guideline for Prescribing Opioids to Treat Pain in Injured Workers. Olympia (WA): L\&I; 2013.
19. University of Michigan Health System. Managing Chronic Nonterminal Pain in Adults Including Prescribing Controlled Substances. Ann Arbor (MI): UHMS; 2011.

20. Zedler B, Xie L, Wang L, et al. Development of a risk index for serious prescription opioid-induced respiratory depression or overdose in Veterans' Health Administration patients. Pain Med. 2015;16;1566-1579.

21. Dasgupta N, Funk M, Proescholdbell S, Hirsch A, Ribisl K, Marshall S. Cohort study of the impact of high-dose opioid analgesics on overdose mortality. Pain Med. Epub 2015 Sep 1.

22. Reddy A, Tayjasanant S, Haider A, et al. The opioid rotation ratio of strong opioids to transdermal fentanyl in cancer patients. Cancer. 2016;122:149-156.

23. Correa D, Farney RJ, Chung F, Prasad A, Lam D, Wong J. Chronic opioid use and central sleep apnea: a review of the prevalence, mechanisms, and perioperative considerations. Anesth Analg. 2015;120:1273-1285.

24. Webster LR, Fine PG. Overdose deaths demand a new paradigm for opioid rotation. Pain Med. 2012;13:571-574.

25. Dowell D, Haegerich TM, Chou R. CDC Guideline for Prescribing Opioids for Chronic Pain - United States, 2016. MMWR Recomm Rep. 2016;65:1-49.

Dove Medical Press encourages responsible, free and frank academic debate. The content of the Journal of Pain Research 'Editorial' section does not necessarily represent the views of Dove Medical Press, its officers, agents, employees, related entities or the Journal of Pain Research editors. While all reasonable steps have been taken to confirm the content of each Editorial, Dove Medical Press accepts no liability in respect of the content of any Editorial, nor is it responsible for the content and accuracy of any Editorial.

Journal of Pain Research

\section{Publish your work in this journal}

The Journal of Pain Research is an international, peer-reviewed, open access, online journal that welcomes laboratory and clinical findings in the fields of pain research and the prevention and management of pain. Original research, reviews, symposium reports, hypothesis formation and commentaries are all considered for publication.

\section{Dovepress}

The manuscript management system is completely online and includes a very quick and fair peer-review system, which is all easy to use. Visit http://www.dovepress.com/testimonials.php to read real quotes from published authors. 